\title{
Partial shade improved the photosynthetic capacity and polysaccharide accumulation of the medicinal plant Bletilla ochracea Schltr.
}

\author{
X.F. YU ${ }^{*, \dagger,}$, X.Y. MING ${ }^{*, \dagger}$, M. XIONG ${ }^{*}$, C. ZHANG ${ }^{* *}$, L.J. YUE*, L. YANG ${ }^{*}$, and C.Y. FAN ${ }^{*}$ \\ College of Landscape Architecture, Sichuan Agricultural University, 611130 Chengdu, China* \\ Industrial Crop Research Institute, Sichuan Academy of Agricultural Sciences, 610300 Chengdu, China**
}

\begin{abstract}
To study the light intensity suitable for Bletilla ochracea Schltr., morphology, photosynthetic parameters, and polysaccharide content of seedlings were evaluated under different light intensities. All shade treatments promoted plant growth and net photosynthetic rate while having no significant effect on transpiration rate. The maximum photochemical efficiency and potential photochemical efficiency reached the lowest values under full sunlight. The electron transport rate and photochemical quenching under shade were significantly higher than those under full light, while nonphotochemical quenching was the highest under full light. This indicated that the shade alleviated photoinhibition in summer and improved the utilization of light. B. ochracea could adapt to different light intensities, enhancing photosynthetic efficiency under low light by improving the electron transport and the degree of opened PSII reaction centers, and adapting to high light by increasing heat dissipation. Plant growth, photosynthesis, and polysaccharide accumulation of $B$. ochracea greatly increased under $76.4 \%$ shade.
\end{abstract}

Keywords: Bletilla ochracea Schltr.; chlorophyll fluorescence; photosynthesis; shade.

\section{Introduction}

Plants convert light energy into chemical energy in vivo through photosynthesis. The optimal light conditions can promote the growth of plants to accumulate dry matter and increase yield (Allakhverdiev 2020, Paradiso et al. 2020). The previous studies have reported that many plants suffer from photoinhibition and photodamage under a high-light environment (Zeng et al. 2017, Liu et al. 2019). Shade is a common gardening measure to protect plants from photoinhibition and oxidative damage caused by excessive light, but excessive shade can reduce yield and quality
(Zivcak et al. 2014). In addition, shade can also alleviate drought, high temperatures, and other adversities (Lopez et al. 2018, Bannister et al. 2021). However, the shade tolerance of plants varies with species and cultivars (Slot et al. 2019). Plants could adapt to varying light conditions through morphological and physiological regulation (Liu et al. 2016, Raza et al. 2020). The leaf is one of the most sensitive parts to light. The morphology and structure of the leaves are usually suitable for their physiological function (Zhang et al. 2016). Thus, the characteristics of leaves can reflect the response and adaptation of plants to the environment (Tang et al. 2020). Leaves under shade are

\section{Highlights}

- Shade promoted leaf growth and photosynthesis capacity of Bletilla ochracea

- The $76.4 \%$ shade was the most suitable for polysaccharide accumulation in B. ochracea

- Shade conditions relieved the photoinhibition that seedlings suffered in summer

Received 24 November 2020 Accepted 6 December 2021

Published online 20 January 2022

${ }^{+}$Corresponding author e-mail: xiaofangyu@sicau.edu.cn

Abbreviations: $\mathrm{Chl}$ - chlorophyll; DM - dry mass; $E$ - transpiration rate; ETR - electron transport rate; $\mathrm{F}_{0}$ - minimal fluorescence; $\mathrm{F}_{\mathrm{m}}$ - maximal chlorophyll fluorescence; $\mathrm{FM}$ - fresh mass; $\mathrm{F}_{\mathrm{v}}$ - variable fluorescence; $\mathrm{F}_{\mathrm{v}} / \mathrm{F}_{0}$ - potential photochemical efficiency; $\mathrm{F}_{\mathrm{v}} / \mathrm{F}_{\mathrm{m}}-$ maximal quantum yield of PSII photochemistry; Mt - saturated leaf mass; NPQ - nonphotochemical quenching; $P_{\mathrm{N}}-$ net photosynthetic rate; $\mathrm{q}_{\mathrm{P}}$ - photochemical quenching coefficient; $\mathrm{Y}_{\mathrm{II}}-$ effective quantum yield of PSII photochemistry.

Acknowledgments: The authors would like to thank the PhD Program of Sichuan Agricultural University (grant no. 63670010).

Xiaofang Yu and Xiaoyu Ming contributed equally to this work.

Conflict of interest: The authors declare that they have no conflict of interest. 
usually larger and thinner than those under sunlight, and the contents of chlorophyll $(a+b)$ [Chl $(a+b)]$, especially Chl $b$, are higher (Lichtenthaler et al. 2007, 2013; Mathur et al. 2018). The photosynthetic rate of shade-tolerant plants can remain relatively high under low-light conditions. Shishido et al. (1987) has reported that Cucumis sativus L. can grow normally under shade conditions because it captures as much light energy as possible to facilitate $\mathrm{CO}_{2}$ fixation and carbohydrate accumulation. Besides, shade-tolerant soybeans showed higher net photosynthetic rates than shade-sensitive soybeans in shade conditions, due to higher PSII activity and energy transport from PSII to PSI (Yao et al. 2017). High shade $(90 \%)$ conditions also upregulated transcripts of antioxidant enzymes of Pinellia ternata to reduce photoinhibition and increased expression of light and auxin signals genes, which significantly increased tuber growth and photosynthesis efficiency as compared to full-light conditions (Xue et al. 2019).

Chl fluorescence parameters can reflect a series of important regulation processes in the photosynthetic apparatus through the measurement of light energy absorption, transmission, dissipation, and distribution in the photosynthesis so as to truly and accurately reveal the influencing mechanisms on photosynthetic processes (Alyemeni et al. 2018). $\mathrm{F}_{\mathrm{v}} / \mathrm{F}_{\mathrm{m}}$ (maximal quantum yield of PSII photochemistry) refers to the efficiency of the open PSII reaction centers capture of excitation energy and the maximum photochemical efficiency of plants (Lichtenthaler et al. 2007). $\mathrm{F}_{\mathrm{v}} / \mathrm{F}_{0}$ (potential photochemical efficiency) denotes the potential activity of PSII photoreaction centers and is an index to measure the photoenergy-utilization capability of plants (Lichtenthaler et al. 2007, Faseela et al. 2020). Higher $F_{v} / F_{0}$ and $F_{v} / F_{m}$ mean the greater light energy utilization potential of plants (Maxwell and Johnson 2000). ETR (electron transport rate) indicates the rate of photosynthetic electron transfer, which is related to the photosynthetic rate of plants (Mathur et al. 2018). Aeschynanthus longicaulis, a shade-tolerant species, suffered from photoinhibition and photodamage under high light conditions and showed significantly lower ETR and $\mathrm{F}_{\mathrm{v}} / \mathrm{F}_{\mathrm{m}}$ (Li et al. 2014). Photochemical quenching $\left(\mathrm{q}_{\mathrm{P}}\right)$ reflects the proportion of opened PSII reaction centers. Higher $\mathrm{q}_{\mathrm{P}}$ facilitates electron transfer and PSII yield (Mathur et al. 2018). Compared to shade-tolerant soybeans, the $\mathrm{q}_{\mathrm{P}}$ of shade-sensitive soybeans showed a significantly higher decrease under 50 and 75\% shade treatments (Yao et al. 2017). Under high or fluctuating light conditions, lesser light energy is consumed for photosynthetic electron transfer in PSII, and more energy is dissipated as heat, which is the most important photoprotection strategy for plants (Endo et al. 2014, Qiao et al. 2021). The redundant light energy dissipated harmlessly as heat is reflected by nonphotochemical quenching (NPQ). Previous studies have shown that plants grown in high light showed higher NPQ values than those grown in low light (Kalmatskaya et al. 2020). $\mathrm{Y}_{\mathrm{II}}$ reflects the effective quantum yield of PSII photochemistry, which is the proportion of light that is absorbed by $\mathrm{Chl}$ for PSII photochemical reaction (Murchie and Lawson 2013). Compared to normal conditions, adversities can decrease the photosynthetic quantum yield (Wan et al. 2011, Wu et al. 2019).

Bletilla ochracea Schltr., a traditional Chinese medicinal plant, is native to forests and shrubs canopy in highaltitude areas and is widely cultivated in China (Yang et al. 2012). There are nine species of Bletilla (Orchidaceae) in the world, including four species of China. The bioactive extracts of the genus are widely used in the pharmaceutical and chemical industries. Studies on chemical constituents and pharmacological activities of the genus were carried out in the 1970s (Jiang et al. 2020). The quality and output value of Bletilla were evaluated by determining the content of polysaccharides. Polysaccharides extracted from B. ochracea tubers, showing antitumor and antioxidation activities, are identified as substitutes for Bletilla striata polysaccharides in the cosmetic and medicine industries (Niu et al. 2020). Previous studies were mainly carried out to determine medicinal efficacy of $B$. ochracea (Yang et al. 2012, Li et al. 2018). To maximize its medicinal and economic value, the yield and quality of $B$. ochracea must be improved. To cultivate high-yield plants, it is necessary to provide a suitable light environment (Yi et al. 2020). Therefore, the growth process, chlorophyll fluorescence, photosynthetic characteristics, and polysaccharide content of $B$. ochracea plants under shade conditions were studied in order to provide a reference for the sustainably used resources of Bletilla in the future.

\section{Materials and methods}

Plant material and growth conditions: Seedlings of Bletilla ochracea were cultivated in Industrial Crop Research Institute of Sichuan Agricultural Sciences (China) on 20 December 2017. The two-year-old seedlings with uniform growth and no disease and insect pests were divided into four groups for each shade treatment. The same water and fertilizer management were used during the experiment.

Experiment design: On 20 February 2018, black sunshade nets were used to provide shade to $B$. ochracea seedlings and the open field-growing environments. The height of the shade nets was $1.5 \mathrm{~m}$ and the distance between each pot was $50 \mathrm{~cm}$ to avoid cross shade. Two seedlings per pot were grown. Four levels were set for different shade environments:

\begin{tabular}{llll}
\hline \multicolumn{2}{l}{ Treatment } & $\begin{array}{l}\text { Shade } \\
{[\%]}\end{array}$ & $\begin{array}{l}\text { Transmittance } \\
{[\%]}\end{array}$ \\
\hline CK & $\begin{array}{l}\text { full illumination } \\
\text { one layer of dense black } \\
\text { shade net }\end{array}$ & 0 & 100 \\
$\mathrm{~A}$ & 94.23 & 5.77 \\
$\mathrm{~B}$ & $\begin{array}{l}\text { two layers of sparse black } \\
\text { shade net }\end{array}$ & 76.41 & 23.59 \\
$\mathrm{C}$ & $\begin{array}{l}\text { thin black sunscreen net } \\
\text { thin }\end{array}$ & 54.93 & 45.07 \\
\hline
\end{tabular}


The illuminometer (1010A, VICTOR, China) was used to determine different shading degrees. We spent several years of research on the cultivation of $B$. ochracea. The vigorous growth period of $B$. ochracea is in late April. Therefore, we started measuring data on 28 April. From 28 April to 17 July, the leaves of seedlings were taken to measure their morphological and physiological indexes every $15 \mathrm{~d}$.

Plant height and leaf traits: Plant height, leaf length, and leaf width were measured with a tape ruler. Ten plants were randomly selected, each of which was measured three times and the average values were taken.

The method of measuring leaf water content was following. First, the leaves were cut randomly without veins, and the surface water was absorbed with filter paper. Second, the leaves were weighed. The fresh mass (FM) of each sample was $0.3 \mathrm{~g}$. Third, the leaves were soaked in ionic water for $5 \mathrm{~h}$ and then we weighed saturated leaf mass (Mt). Finally, leaves were kept in an oven at $105^{\circ} \mathrm{C}$ for $30 \mathrm{~min}$, dried at $80^{\circ} \mathrm{C}$ for $24 \mathrm{~h}$, and weighed for dry mass $(\mathrm{DM})$. Relative leaf water content $[\%]=$ $[(\mathrm{FM}-\mathrm{DM}) /(\mathrm{Mt}-\mathrm{DM})] \times 100$.

The spectrophotometer (UV1800, Shanghai Jinpeng, China) was used to determine chlorophyll content (Wellburn 1994).

Polysaccharide content: The tubers were harvested on 17 July, dried, ground, and passed through sieve (250 \pm $9.9 \mu \mathrm{m})$. The tuber powder was taken to determine of polysaccharide content of B. ochracea, based on the method of Li et al. (2018). First, the crude polysaccharide solution was extracted. The tuber powder $(0.2 \mathrm{~g})$ was weighed, placed in a round bottom flask, and $50 \mathrm{ml}$ of water was added. The round bottom flask was weighed, solution heated and refluxed for $1 \mathrm{~h}$, and then cooled. The flask was weighed for the second time, water was added to make up the reduced mass, well shaken, and filtered. To $5 \mathrm{ml}$ of filtrate, $30 \mathrm{ml}$ of absolute ethanol was added, shaken well, and kept for $1 \mathrm{~h}$. Then the mixture was centrifuged at 3,000 rpm for $15 \mathrm{~min}$, supernatant was removed, and precipitate was dissolved in hot water. The resultant solution was cooled, and the volume was made up to $100 \mathrm{ml}$ in a volumetric flask.

Secondly, $100 \mathrm{~g}$ of solid glucose (analytical grade) was precisely weighed and dissolved in $100 \mathrm{ml}$ of deionized water. Glucose solutions of $0.05,0.1,0.2,0.4,0.5,0.8$, and $1.0 \mathrm{ml}$ of $1 \mathrm{mg}$ (glucose) $\mathrm{ml}^{-1}$ were precisely measured and placed in 10-ml tube. Water was added to make up the volume to $2 \mathrm{ml}$ for each solution and shaken well. To prepare anthrone sulfuric acid solution, $0.1 \mathrm{~g}$ of anthrone was accurately weighed and dissolved in $100 \mathrm{ml}$ of $80 \%$ concentrated sulfuric acid. Then, $4.5 \mathrm{ml}$ of anthrone sulfuric acid solution was precisely added and mixed well. Then, it was heated in boiling water bath for $10 \mathrm{~min}$ and taken out. It was quickly cooled in running water for $10 \mathrm{~min}$. The absorbance was measured at $625 \mathrm{~nm}$ by UV-spectrophotometer (Evolution 260 Bio, Thermo Scientific, Germany). The standard curve was drawn with glucose concentration $(0,0.05,0.2,0.4,0.5,0.8$,
$1 \mathrm{mg} \mathrm{g}^{-1}$ ) as the horizontal coordinate and the absorbance as the vertical coordinate. The linear regression equation is $\mathrm{y}=1.2651 \mathrm{x}+0.1223, r=0.9982$, showing a good linear relationship. After that, polysaccharide extract of $B$. ochracea was taken to measure the polysaccharide content.

Photosynthesis parameters: Photosynthetic rate and Chl fluorescence were measured from 8:00 to 18:00 h. Portable photosynthetic gas analyzer ( $L i-6100, L I-C O R$, USA) was used to measure net photosynthetic rate and transpiration rate. Plants grown under different shade degrees were randomly selected. The leaves with the same leaf position (three plants per treatment, three leaves per plant, and three times per leaf) were measured every $2 \mathrm{~h}$ between 8:00 to $18: 00 \mathrm{~h}$.

Chl fluorescence measurements: The $\mathrm{Chl}$ fluorescence parameters of leaves were measured by a portable plant Chl fluorescence analyzer (Junior PAM, Walz, Germany). Each time fluorescence parameters were determined in six leaves. The leaves were dark-adapted for $30 \mathrm{~min}$ before each measurement. For light-saturation curve measurement, the light intensity gradient was set at 90, $125,190,285,420,625,820$; and 1,150 $\mu \mathrm{mol}$ (photon) $\mathrm{m}^{-2} \mathrm{~s}^{-1}$. The electron transport rate (ETR), photosynthetic quantum yield $\left(\mathrm{Y}_{\mathrm{II}}\right)$, photochemical quenching coefficient $\left(\mathrm{q}_{\mathrm{P}}\right)$, and the nonphotochemical quenching coefficient (NPQ) were calculated (Maxwell and Johnson 2000): $\mathrm{ETR}=0.5 \times \alpha \times \mathrm{PAR} \times \mathrm{Y}_{\mathrm{II}}, \mathrm{Y}_{\mathrm{II}}=\left(\mathrm{F}_{\mathrm{m}}-\mathrm{F}_{\mathrm{t}}{ }^{\prime}\right) / \mathrm{F}_{\mathrm{m}}{ }^{\prime}, \mathrm{q}_{\mathrm{P}}=\left(\mathrm{F}_{\mathrm{m}}{ }^{\prime}-\mathrm{F}_{\mathrm{t}}{ }^{\prime}\right) /$ $\left(F_{m}{ }^{\prime}-F_{0}{ }^{\prime}\right), N P Q=\left(F_{m}-F_{m}{ }^{\prime}\right) / F_{m}{ }^{\prime}$.

Statistics analysis: The data is presented as mean \pm standard deviation (SD) using Microsoft Excel (version 2010, Microsoft, USA). Photosynthesis parameters and parameters of $\mathrm{Chl}$ fluorescence were analyzed by one-way analysis of variance $(A N O V A)$. Leaf characteristics, plant growth, $\mathrm{Chl}(a+b)$, and $\mathrm{Chl} a / b$ were analyzed by repeated ANOVA using SPSS software (version 19.0, SPSS, USA). All the significant differences between means were detected by Duncan's multiple range test $(P<0.05)$. All the graphs were drawn by Origin (version 8.0, OriginLab, USA).

\section{Results}

Leaf characteristics and plant growth: The plant heights under different shade treatments are shown in Table 1. The plants height under all treatments increased rapidly before 15 May and successively showed a stable increasing trend till 17 July. The plant heights under all the shade treatments were significantly higher than those under full-light treatment. Plant height reached the maximum under $76.4 \%$ shade. These data demonstrated that light intensity significantly affected plant height and the shade promoted plant elongation.

The growth of leaves length was first increasing rapidly and becoming stable gradually in all shade treatments (Table 2). Leaves under full-light conditions were significantly different from those under shade treatments 
analyzed by one-way $A N O V A$. Leaves were also promoted by shade and the leaves under $76.4 \%$ shade were the longest.

Leaves of $B$. ochracea under shade conditions were wider than those under full light (Table 3). The width of leaves under shade treatments were significantly different from those under full light as analyzed by $A N O V A$ for repeated measurement and the width under $76.4 \%$ shade was the highest. The width of leaves under different shade degrees were as following: $76.4 \%$ shade $>94.2 \%$ shade $>$ $54.9 \%$ shade.

Leaf water content is an important indicator of leaf status. It can be seen from Table 4 that the water contents of leaves under shade were higher than those under full light. Through ANOVA for repeated measurement, a significant difference between CK and shade treatments was found. The leaf water contents for each treatment under different shade degrees were as follows: $94.2 \%$ shade $>$ $76.4 \%$ shade $>54.9 \%$ shade.

Chl content: Under shade conditions, the Chl $(a+b)$ contents were significantly higher than those under fulllight condition (Table 1S, supplement). The Chl $(a+b)$ contents under all the conditions decreased rapidly on 15 May compared to the values on 28 April, since then they successively increased until 30 May, and then they

Table 1. Changes of plant height $[\mathrm{cm}]$ of Bletilla ochracea under different shade treatments. Data are means $\pm \mathrm{SD}$. Different lowercase letters represent significant differences between treatments by Duncan's test $(P<0.05)$. A, B, C, and CK indicate that corresponding shade rates are $94.2 \%, 76.4 \%, 54.9 \%$, and $0 \%$ (full sunlight).

\begin{tabular}{lllllll}
\hline Treatment & 28 April & 15 May & 30 May & 14 June & 2 July & 17 July \\
\hline A & $12.13 \pm 0.13^{\mathrm{b}}$ & $17.70 \pm 0.31^{\mathrm{a}}$ & $21.56 \pm 0.48^{\mathrm{b}}$ & $23.58 \pm 1.16^{\mathrm{a}}$ & $25.19 \pm 1.36^{\mathrm{a}}$ & $25.94 \pm 2.98^{\mathrm{ab}}$ \\
B & $13.84 \pm 0.34^{\mathrm{a}}$ & $18.40 \pm 0.86^{\mathrm{a}}$ & $27.34 \pm 0.53^{\mathrm{a}}$ & $27.48 \pm 2.29^{\mathrm{a}}$ & $28.53 \pm 1.10^{\mathrm{a}}$ & $30.23 \pm 1.64^{\mathrm{a}}$ \\
C & $11.34 \pm 0.64^{\mathrm{b}}$ & $16.99 \pm 1.09^{\mathrm{a}}$ & $21.97 \pm 0.42^{\mathrm{b}}$ & $23.14 \pm 1.39^{\mathrm{a}}$ & $24.23 \pm 0.60^{\mathrm{a}}$ & $25.20 \pm 1.02^{\mathrm{b}}$ \\
CK & $10.51 \pm 0.30^{\mathrm{c}}$ & $15.87 \pm 0.39^{\mathrm{b}}$ & $18.50 \pm 0.87^{\mathrm{c}}$ & $20.94 \pm 1.36^{\mathrm{b}}$ & $21.79 \pm 1.74^{\mathrm{b}}$ & $22.06 \pm 2.03^{\mathrm{b}}$ \\
\hline
\end{tabular}

Table 2. Length of leaves [cm] of Bletilla ochracea under different shade treatments. Data are means \pm SD. Different lowercase letters represent significant differences between treatments by Duncan's test $(P<0.05)$. A, B, C, and CK indicate that corresponding shade rates are $94.2 \%, 76.4 \%, 54.9 \%$, and $0 \%$ (full sunlight).

\begin{tabular}{lrlllll}
\hline Treatment & \multicolumn{1}{c}{ 28 April } & 15 May & 30 May & 14 June & 2 July & 17 July \\
\hline A & $8.17 \pm 0.11^{\mathrm{b}}$ & $11.38 \pm 0.65^{\mathrm{a}}$ & $18.33 \pm 0.72^{\mathrm{a}}$ & $20.61 \pm 0.06^{\mathrm{b}}$ & $21.78 \pm 0.51^{\mathrm{b}}$ & $22.23 \pm 1.63^{\mathrm{a}}$ \\
B & $10.08 \pm 0.28^{\mathrm{a}}$ & $12.52 \pm 1.08^{\mathrm{a}}$ & $18.14 \pm 2.16^{\mathrm{a}}$ & $20.26 \pm 1.23^{\mathrm{a}}$ & $22.34 \pm 0.24^{\mathrm{a}}$ & $23.94 \pm 0.85^{\mathrm{a}}$ \\
C & $9.48 \pm 0.24^{\mathrm{a}}$ & $12.46 \pm 0.44^{\mathrm{a}}$ & $17.83 \pm 0.83^{\mathrm{a}}$ & $17.92 \pm 0.62^{\mathrm{c}}$ & $20.24 \pm 1.43^{\mathrm{a}}$ & $22.69 \pm 0.53^{\mathrm{a}}$ \\
CK & $7.37 \pm 0.19^{\mathrm{c}}$ & $10.37 \pm 0.37^{\mathrm{b}}$ & $16.47 \pm 0.55^{\mathrm{b}}$ & $16.88 \pm 0.04^{\mathrm{c}}$ & $18.29 \pm 1.01^{\mathrm{b}}$ & $20.46 \pm 1.51^{\mathrm{b}}$ \\
\hline
\end{tabular}

Table 3. Width of leaves [cm] of Bletilla ochracea under different shade treatments. Data are means $\pm \mathrm{SD}$. Different lowercase letters represent significant differences between treatments by Duncan's test $(P<0.05)$. A, B, C, and CK indicate that corresponding shade rates are $94.2 \%, 76.4 \%, 54.9 \%$, and $0 \%$ (full sunlight).

\begin{tabular}{lllllll}
\hline Treatment & 28 April & 15 May & 30 May & 14 June & 2 July & 17 July \\
\hline A & $1.30 \pm 0.17^{\mathrm{a}}$ & $1.53 \pm 0.03^{\mathrm{a}}$ & $1.74 \pm 0.24^{\mathrm{a}}$ & $1.88 \pm 0.02^{\mathrm{a}}$ & $1.99 \pm 0.12^{\mathrm{a}}$ & $2.17 \pm 0.12^{\mathrm{a}}$ \\
B & $1.44 \pm 0.26^{\mathrm{a}}$ & $1.52 \pm 0.11^{\mathrm{a}}$ & $1.67 \pm 0.13^{\mathrm{a}}$ & $1.71 \pm 0.01^{\mathrm{a}}$ & $1.84 \pm 0.26^{\mathrm{a}}$ & $1.92 \pm 0.08^{\mathrm{a}}$ \\
C & $1.41 \pm 0.14^{\mathrm{a}}$ & $1.80 \pm 0.23^{\mathrm{a}}$ & $1.90 \pm 0.10^{\mathrm{a}}$ & $2.07 \pm 0.09^{\mathrm{a}}$ & $2.08 \pm 0.06^{\mathrm{a}}$ & $2.17 \pm 0.88^{\mathrm{a}}$ \\
CK & $0.83 \pm 0.13^{\mathrm{b}}$ & $1.30 \pm 0.08^{\mathrm{b}}$ & $1.36 \pm 0.06^{\mathrm{b}}$ & $1.62 \pm 0.06^{\mathrm{b}}$ & $1.68 \pm 0.04^{\mathrm{b}}$ & $1.72 \pm 0.09^{\mathrm{b}}$ \\
\hline
\end{tabular}

Table 4. Leaf water contents [\%] of Bletilla ochracea under different shade treatment. Data are means \pm SD. Different lowercase letters represent significant differences between treatments by Duncan's test $(P<0.05)$. A, B, C, and CK indicate that corresponding shade rates are $94.2 \%, 76.4 \%, 54.9 \%$, and $0 \%$ (full sunlight).

\begin{tabular}{lllllll}
\hline Treatment & 28 April & 15 May & 30 May & 14 June & 2 July & 17 July \\
\hline A & $83.51 \pm 0.12^{\mathrm{a}}$ & $79.29 \pm 0.36^{\mathrm{a}}$ & $80.57 \pm 1.37^{\mathrm{a}}$ & $76.39 \pm 0.71^{\mathrm{a}}$ & $80.64 \pm 1.21^{\mathrm{a}}$ & $74.14 \pm 0.82^{\mathrm{a}}$ \\
B & $80.03 \pm 0.16^{\mathrm{b}}$ & $77.66 \pm 1.02^{\mathrm{a}}$ & $77.16 \pm 1.41^{\mathrm{b}}$ & $75.97 \pm 0.71^{\mathrm{a}}$ & $75.75 \pm 0.60^{\mathrm{b}}$ & $72.17 \pm 1.11^{\mathrm{a}}$ \\
C & $77.29 \pm 0.11^{\mathrm{c}}$ & $74.02 \pm 0.57^{\mathrm{b}}$ & $75.38 \pm 1.94^{\mathrm{b}}$ & $72.41 \pm 0.87^{\mathrm{b}}$ & $73.60 \pm 1.90^{\mathrm{b}}$ & $69.60 \pm 1.07^{\mathrm{b}}$ \\
CK & $76.49 \pm 0.16^{\mathrm{c}}$ & $72.07 \pm 1.64^{\mathrm{b}}$ & $71.40 \pm 0.79^{\mathrm{c}}$ & $66.85 \pm 0.49^{\mathrm{c}}$ & $70.36 \pm 0.31^{\mathrm{c}}$ & $72.35 \pm 0.29^{\mathrm{a}}$ \\
\hline
\end{tabular}


showed a steady trend. Through ANOVA for repeated measurements, there is a significant difference between $\mathrm{CK}$ and other shade treatments. It can be seen from Table 2S (supplement) that the trend was not the same throughout the determination period. On 28 April, the value of $\mathrm{Chl} a / b$ in $\mathrm{CK}$ was higher than the values under shade treatments and further increased on 15 May. From 30 May onwards, the $\mathrm{Chl} a / b$ decreased steadily in CK. The value of $\mathrm{Chl} a / b$ for $\mathrm{CK}$ was higher than shade treatments at all data points except two, on 15 May and 30 May. The change of the ratio of $\mathrm{Chl} a / b$ is an adaptation to the different shade environments. The $\mathrm{Chl} a / b$ reached the highest value in the middle of May.

Photosynthesis parameters: The changes in $P_{\mathrm{N}}$ were of unimodal type under different shade treatments, without midday depression of photosynthesis (Fig. 1A). From 8:00 to $12: 00 \mathrm{~h}$, the values of $P_{\mathrm{N}}$ were in order of $76.4 \%$ shade $>94.2 \%$ shade $>54.9 \%$ shade $>$ CK. From 14:00 to $18: 00 \mathrm{~h}$, the values of $P_{\mathrm{N}}$ were in order of $94.2 \%$ shade $>$ $76.4 \%$ shade $>54.9 \%$ shade $>C K$.

$P_{\mathrm{N}}$ values in treatments $\mathrm{A}$ and $\mathrm{B}$ were always significantly higher than those in full-light treatment and there was no significant difference between treatments $\mathrm{A}$ and B. From 10:00 to $16: 00 \mathrm{~h}$, there was a significant difference between full light and $54.9 \%$ shade. All treatments reached the peak value at 12:00 h. The lowest peak value was in the full-light treatment, which was significantly lower than shade treatments. At 12:00 h, the maximum $P_{\mathrm{N}}$ was under $76.4 \%$ shade, which was 1.43 times higher than that under CK. The results showed that shade treatment significantly promoted photosynthesis capacity of $B$. ochracea. As shown in Fig. $2 B$, the transpiration rates $(E)$ under all the treatments showed the similar tendencies and reached the highest value at 12:00 h and then showed a downward trend. In the morning, the $E$ values under CK were significantly higher than those under shade treatments. The minimum values appeared at 18:00 h (except for 94.2\% shade). The $E$ values showed no significant difference between all treatments at 18:00 h.
From the results, it can be inferred that shade had a little effect on $E$ of $B$. ochracea.

Chl fluorescence: Parameters of Chl fluorescence can quickly and sensitively detect the effects of environment variations on plant photosynthesis. Under different light conditions, the values of $F_{v} / F_{m}$ showed the $V$-shaped change. It can be seen from Fig. $2 A$ that the $F_{v} / F_{m}$ values under different shade treatments decreased in the forenoon and then increased slowly. Throughout the day, the $F_{v} / F_{m}$ value of each treatment was the highest at 8:00 $\mathrm{h}$ and the lowest at 12:00 h. Normally, the $\mathrm{F}_{\mathrm{v}} / \mathrm{F}_{\mathrm{m}}$ values of higher plants reach 0.75-0.85 (Maxwell and Johnson 2000). $\mathrm{F}_{\mathrm{v}} / \mathrm{F}_{\mathrm{m}}$ values under shade treatments were significantly higher than those under full-light condition. $\mathrm{F}_{\mathrm{v}} / \mathrm{F}_{\mathrm{m}}$ values under $94.2 \%$ and $76.4 \%$ shade conditions have been relatively steady and maintained at a relatively high level, while there was no significant difference in $F_{v} / F_{m}$ values between three shade conditions. $\mathrm{F}_{\mathrm{v}} / \mathrm{F}_{\mathrm{m}}$ under full-light treatment decreased to 0.44 at $12: 00 \mathrm{~h}$, which was much lower than those under shade treatments. According to these data, full light caused photoinhibition of seedlings and shade conditions were helpful to alleviate the photoinhibition under strong light in summer.

Under different shade treatments (Fig. $2 B$ ), the $\mathrm{F}_{\mathrm{v}} / \mathrm{F}_{0}$ values decreased from 8:00 to $12: 00 \mathrm{~h}$ and then increased till 18:00 h. The $F_{v} / F_{0}$ value under $94.2 \%$ shade treatment was the highest at noon, while that under $\mathrm{CK}$ was the lowest. The values of $F_{v} / F_{0}$ under full light were always lower than those under shade treatments. During the day, there was no significant difference in the $F_{v} / F_{0}$ values between $76.4 \%$ and $54.9 \%$ shade treatment. Before 14:00 h, 94.2\% shade treatment had the highest $F_{v} / F_{0}$ values and was significantly higher than other treatments. At 16:00 h, the $\mathrm{F}_{\mathrm{v}} / \mathrm{F}_{0}$ values of three shade treatments were significantly higher than full sunlight $(P<0.05)$. At 18:00 $h$, the $F_{v} / F_{0}$ value in $54.9 \%$ shade reached the highest value in the whole experiment, which was 1.88 times and 1.36 times of that in CK and 94.2\% shade, respectively.

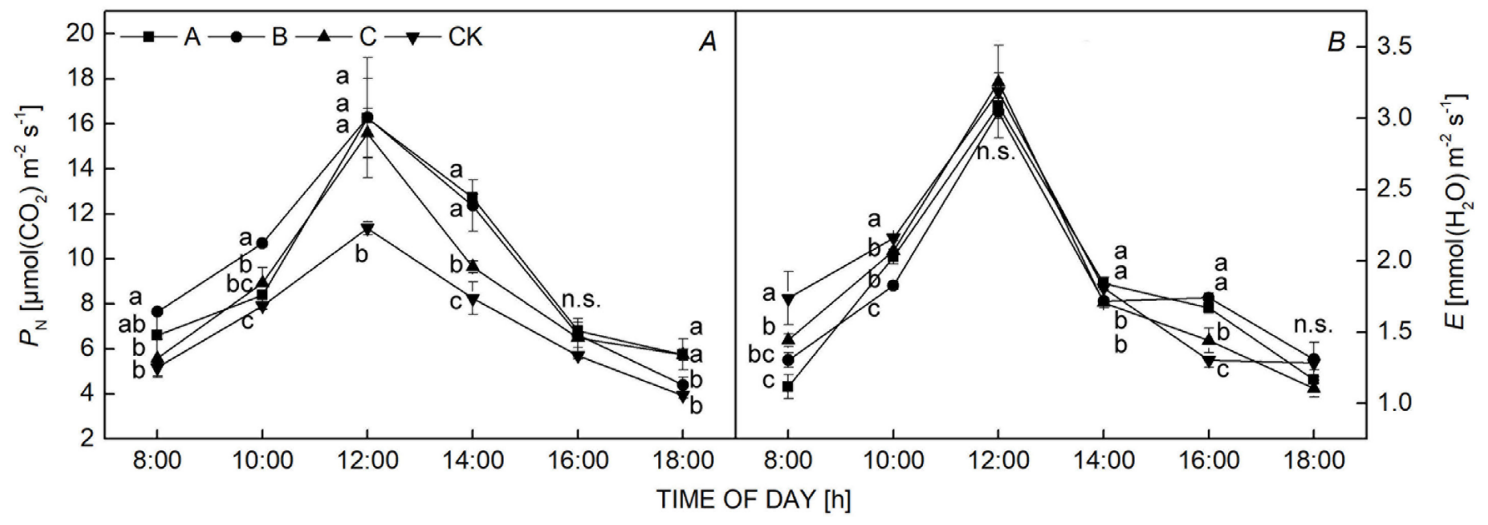

Fig. 1. Photosynthetic parameters of Bletilla ochracea under different shade treatments. Data are means $\pm \mathrm{SD}(n=3)$. A, B, C, and CK indicate that corresponding shade rates are $94.2 \%, 76.4 \%, 54.9 \%$, and $0 \%$ (full sunlight). Parameters of photosynthesis on $17 \mathrm{July}$ : $(A)$ photosynthetic rate $\left(P_{\mathrm{N}}\right)$ and $(B)$ transpiration rate $(E)$. Different lowercase letters represent significant differences between treatments by Duncan's test $(P<0.05)$. The n.s. indicates no significant difference between treatments. 


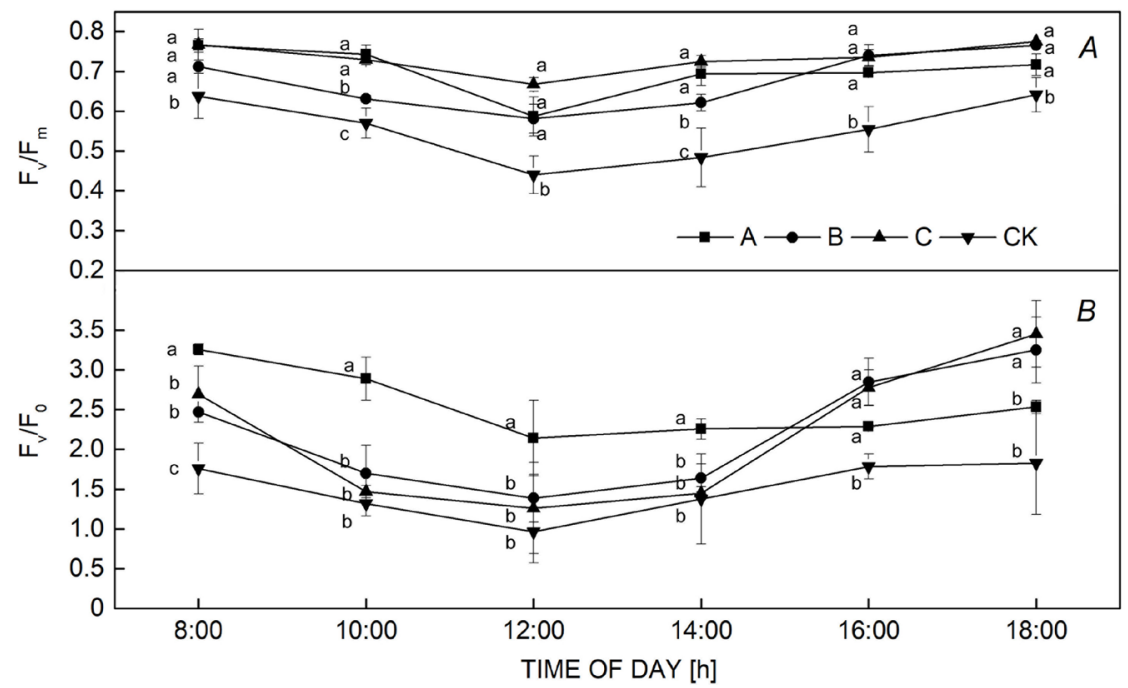

Fig. 2. Changes in photochemical efficiency of Bletilla ochracea under different shade treatments. Data are means $\pm \mathrm{SD}(n=3)$. A, B, C, and CK indicate that corresponding shade rates are $94.2 \%, 76.4 \%, 54.9 \%$, and $0 \%$ (full sunlight). Different lowercase letters represent significant differences between treatments by Duncan's test $(P<0.05)$. The n.s. indicates no significant difference between treatments. $F_{v} / F_{0}-$ potential photochemical efficiency; $\mathrm{F}_{\mathrm{v}} / \mathrm{F}_{\mathrm{m}}$ - maximal quantum yield of PSII photochemistry.
As photosynthetic effective radiation increased, ETR continued to increase (Fig. $3 A$ ). Under all light intensities, the ETR values under shade conditions were significantly higher than those under full light. The electron transport capacity of seedlings grown under full light was lower than that of plants grown under shade conditions. The $\mathrm{q}_{\mathrm{p}}$ of each treatment decreased with the increase of photosynthetic effective radiation, the values of $\mathrm{q}_{\mathrm{P}}$ were in order of $94.2 \%$ shade $>54.9 \%$ shade $>76.1 \%$ shade $>$ CK (Fig. $3 B$ ). Starting from $125 \mu \mathrm{mol}\left(\right.$ photon) $\cdot \mathrm{m}^{-2} \cdot \mathrm{s}^{-1}$, the values of $\mathrm{q}_{\mathrm{P}}$ under $94.2 \%$ shade were always significantly higher than those under treatments B and C. There was no significant difference between treatments B and C. Shade raised the openness of PSII reaction centers. The $\mathrm{Y}_{\text {II }}$ of B. ochracea decreased with increasing photosynthetic effective radiation (Fig. 3C). The $\mathrm{Y}_{\mathrm{II}}$ of $54.9 \%$ and $76.4 \%$ shade was higher than that under treatments $\mathrm{A}$ and $\mathrm{CK}$. There was no significant difference between CK and $94.2 \%$ shade, at all light intensities, and it was always significantly lower than those under $54.9 \%$ shade. At $1,150 \mu \mathrm{mol}$ (photon) $\mathrm{m}^{-2} \mathrm{~s}^{-1}$, the $\mathrm{Y}_{\text {II }}$ in $54.9 \%$ shade was the highest, and the minimum $\mathrm{Y}_{\mathrm{II}}$ was 1.60 times higher than that in $\mathrm{CK}$. The NPQ values under $54.9 \%$ shade were the lowest and the NPQ values under CK were the highest (Fig. $3 D$ ). There was no significant difference between $\mathrm{A}$ and $\mathrm{B}$ treatments, but it was significantly higher than those under $54.9 \%$ shade.

Polysaccharide content: The polysaccharide contents were 51.2 (94.2\% shade), 70.4 (76.4\% shade), 60.7 (54.9\% shade), and $60.1 \%$ (CK) of total sugar, respectively (Fig. 4). The polysaccharide content at $76.4 \%$ shade significantly increased by $17.1 \%$ compared with $\mathrm{CK}$. The polysaccharide content in the medicinal material may be related to the light intensity.

\section{Discussion}

The change of morphological traits is obvious when plants develop under different light environments. In our experiment, the shade also had a tremendous effect on photosynthetic process in plants. The plants height, leaf length, and leaf width increased under all shade conditions (Tables 1, 2, and 3), which could be attributed to the increase of photosynthetic activity (Qiao et al. 2021). The growth rates under $76.4 \%$ and $94.2 \%$ shade were more rapid compared to $\mathrm{CK}$ (Table 1), showing that moderately and highly shaded environments promoted the growth of B. ochracea, similar to Leymus chinensis (Yang et al. 2018) and Phoebe bournei (Tang et al. 2020). In this experiment, the increasing trend of plant height, leaf length, and leaf width slowed down since 2 July (Tables 1 , 2 , and 3 ). The possible reason could be that morphological adaptation in weak light environment has already occurred (Terashima et al. 2011). Meanwhile, high light and temperature in summer were not conducive to plant growth under shade conditions (Takahashi and Murata 2008). Some studies have reported that photoinhibition may lead to the decrease of photosynthesis causing the decrease of plant growth rate under conditions of excessive light intensity (Fang et al. 2012). In the study, compared with full-light treatment, $76.4 \%$ and $94.2 \%$ shade conditions obviously enhanced the plant heights and leaf growth. The earlier research has shown that in the lower canopy of the rainforest, only by evolving larger plant leaves and horizontal leaf orientation, plants can capture light energy to the maximum extent (Lichtenthaler et al. 2007). Therefore, under low-light conditions, some plants will allocate photosynthetic products to leaf growth to promote photosynthesis, and ultimately ensure normal plant growth (Terashima et al. 2011). Shade not only changed the light intensity but also changed the air moisture and velocity in plant microenvironment (Lopez et al. 2018). Ahemd et al. (2016) showed that shade conditions could lower greenhouse temperature and humidity of greenhouse air to reduce energy and water consumption. Leaf water content is an important plant functional trait which can show water status and the degree of metabolism in leaves (Wang et al. 2019, Zhou et al. 2021). Our results showed that shade could increase the water content of leaves to keep plants 


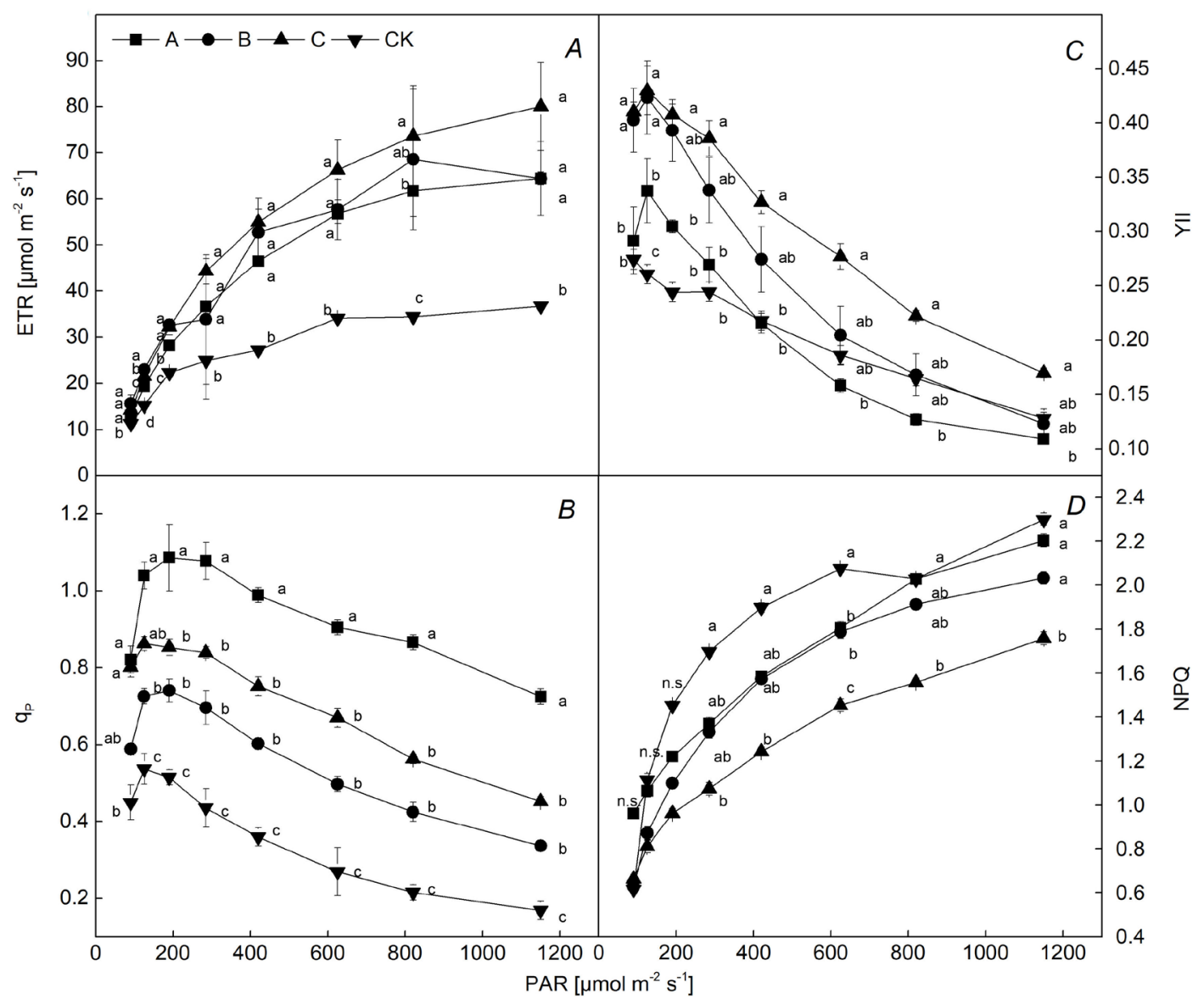

Fig. 3. Changes in fluorescence parameters of Bletilla ochracea under different shade treatments. Data are means $\pm \operatorname{SD}(n=3)$. A, B, C, and CK indicate that corresponding shade rates are $94.2 \%, 76.4 \%, 54.9 \%$, and $0 \%$ (full sunlight). Different lowercase letters represent significant differences between treatments by Duncan's test $(P<0.05)$. The n.s. indicates no significant difference between treatments. The change of $\mathrm{Chl}$ fluorescence parameters with increasing photosynthetic effective radiation: $(A)$ Electron transport rate (ETR); $(B)$ photochemical quenching $\left(\mathrm{q}_{\mathrm{P}}\right) ;(C)$ actual photosynthetic quantum yield $\left(\mathrm{Y}_{\mathrm{II}}\right) ;(D)$ nonphotochemical quenching (NPQ).

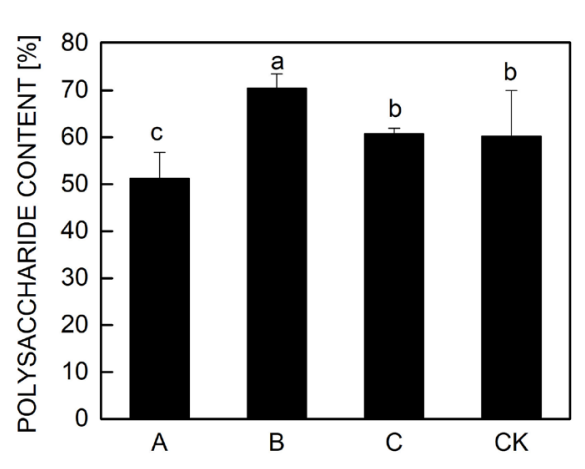

Fig. 4. Changes in polysaccharide content of Bletilla ochracea under different shade treatments. Data are means $\pm \mathrm{SD}(n=3)$. Different lowercase letters represent significant differences between treatments by Duncan's test $(P<0.05)$. A, B, C, and CK indicate that corresponding shade rates are $94.2 \%, 76.4 \%$, $54.9 \%$, and $0 \%$ (full sunlight).

in a good water status. In general, shade facilitates the cultivation of seedlings in summer.
Chlorophylls are the most important pigments in plants with the function of absorbing and transmitting light. The content and proportion of Chls are important indexes for plants to adapt to different environmental factors. Generally, leaves under shade tend to have a larger light-harvesting complex, and thus lower Chl $a / b$ values and higher Chl $(a+b)$ contents (Yang et al. 2019). Chl $(a+b)$ content depends not only on the environmental conditions but also on the plant species (Lichtenthaler et al. 2013, Zivcak et al. 2014, Zhang et al. 2016). In this experiment, shade environments increased the Chl $(a+b)$ content of $B$. ochracea (Table 1S). A large number of studies have reported that the Chl $(a+b)$ content of shade-intolerant plants could be lowered under weaklight conditions (Lopez et al. 2018, Mathur et al. 2018). With the increasing shade degree, the Chl $(a+b)$ content of $B$. ochracea increased. Higher Chl $(a+b)$ contents and thinner leaves help them capture light energy to survive under shade. One of the important properties of Chls is the selective absorption of light. Chl $a$ and $\mathrm{Chl} b$ have different absorption spectra. The absorption of $\mathrm{Chl} a$ in red light (longer light wavelength) is wider than $\mathrm{Chl} b$, while 
the absorption of $\mathrm{Chl} b$ in blue and purple light is wider than Chl $a$ (Lü et al. 2013). The decrease of Chl $a / b$ values can improve the utilization efficiency of blue and purple light and adapt to the growth in shade (Lü et al. 2013). In this study, the Chl $a / b$ values of leaves decreased with the increase of shade degree and the Chl $a / b$ values were significantly lower than that under full light since 15 May (Table 2S). The results showed that under the conditions of high shade, the varying pigment contents were helpful for plants to improve the light trapping and utilization capability of chlorophylls. It is one of the adaptation mechanisms of plants induced in the shade environments.

B. ochracea is native to forests and shrubs canopy at high-altitude areas in China, growing in shady and cool habitat. In order to choose the light intensity conducive to the seedlings' photosynthesis, we measured the photosynthetic rate and transpiration rate in mid-July when there was high temperature and strong light. Our results showed that $B$. ochracea could tolerate both full light and weak light environment. Besides, shade environments facilitated the photosynthesis activity and plant growth. A large number of studies have reported that shade conditions could optimize photosynthesis capacity of plants, such as Myrica rubra (Zeng et al. 2017), Torreya grandis (Lin et al. 2019), and Phoebe bournei (Tang et al. 2020). However, different plants tolerate different shade degrees (Shao et al. 2014, Yang et al. 2018). In this study, the diurnal curves of $P_{\mathrm{N}}$ were of a unimodal type (Fig. 1A), which indicated that there was no midday depression of photosynthesis during the treatments. Contrastingly, some earlier studies have shown that excessive radiation leads to photoinhibition and reduction of PSII activity, and even midday depression of photosynthesis, making the photosynthetic curve bimodal (Zhao et al. 2012, Liu et al. 2019, Yang et al. 2019). Considering medicinal plants yield and irrigation costs, evapotranspiration can play a guiding role in the cultivation of medicinal plants (Ahemd et al. 2016). High light induced leaf temperature rise and excessive transpiration can lead to water deficit, decrease of photosynthetic rate and even plant death (Liu et al. 2019, Yang et al. 2019). Over-shading also limits transpiration, which can limit photosynthetic rate and affect plant growth, too (Shao et al. 2014). In our study, the diurnal variation curves of $E$ were consistent with the diurnal variation curves of $P_{\mathrm{N}}$ (Fig. 1B). Besides, shade significantly increased the photosynthetic rate of seedlings, but had no significant effect on transpiration rate. According to our study, shade environments facilitated the improvement of photosynthesis, and high shade conditions $(94.2 \%$ and $76.4 \%$ shade) were more effective (Fig. $1 A$ ). The possible reasons are (1) shade increases light energy-utilization efficiency and electron transport rate; (2) shade reduces photoinhibition.

Plants have evolved a variety of photoprotection strategies to adapt to fluctuating and high-light conditions. Photoinhibition occurs during the day and the degree of photoinhibition increases with light intensity (Ruban et al. 2012). Photodamage of photosynthetic apparatus is inevitable, and photosynthetic system is in the process of constant damage and repair cycle (Takahashi and Murata 2008). Previous studies have shown that under a weak light, the repair rate of D1 protein is higher (Allakhverdiev and Murata 2004). Thus, we speculated the seedlings under shade treatment were less photoinhibited and had a higher electron transfer rate, which resulted in higher $P_{\mathrm{N}}$. A strong light environment is always accompanied by high temperature in summer. High temperature stress could limit photosynthesis activity due to decreased electron transfer rate and $\mathrm{CO}_{2}$ fixation (Ashraf and Harris 2013). Moderate shade can improve the plant microenvironment to protect plants from oxidative damage under high temperature and strong light, thereby protecting the PSII reaction centers, avoiding midday depression of photosynthesis and leaf burns (Liu et al. 2019). Shade can also improve the utilization rate of light energy and improve the photosynthetic activity (Chen et al. 2017). In this experiment, the diurnal variation curves of $F_{v} / F_{m}$ and $F_{v} / F_{0}$ were in the $V$ shape (Fig. 2), indicating that utilization rate of light energy was lowest at 12:00 h. In high sunlight (noon), stomata also close leading to reduced $\mathrm{CO}_{2}$ exchange and reduction in photosynthesis. $\mathrm{F}_{\mathrm{v}} / \mathrm{F}_{\mathrm{m}}$ and $\mathrm{F}_{\mathrm{v}} / \mathrm{F}_{0}$ values under full light were always the lowest, which is similar to Citrus reticulata (Medina et al. 2002). Shade conditions improved the utilization rate of light energy and were helpful to alleviate the photoinhibition. Plants have a strong photoprotection capability, probably owing to the photoprotection measures like NPQ, reactive oxygen scavenging, photorespiration, and cyclic electron flow (Ruban et al. 2012). The NPQ increased with the increase of photosynthetic effective radiation (Fig. 3D). With the increase of light intensity, more light energy absorbed by leaves was dissipated as heat, which reduced the light energy used for photosynthetic electron transfer. In order to reduce the damage of active oxygen to photosynthetic apparatus, the increase of NPQ can form a protective mechanism to dissipate excess light energy and avoid the damage of photoreaction centers (Gururani et al. 2015). Under full light, the $\mathrm{q}_{\mathrm{p}}$ values were the lowest and the NPQ values were the highest (Fig. 3B,D), which demonstrated that B. ochracea adapted to the strong light environment by dissipating heat under full-light condition. Thus, B. ochracea could not only adapt to weak-light condition, but also tolerate full-light condition.

The ETR values under full light were significantly lower than those under shade treatments (Fig. $3 A$ ). It is shown that $B$. ochracea leaves grown under shade conditions improved the ability of utilization of absorbed light energy. It is also possible that shade improved the openness of the PSII reaction centers to increase the total amount of light energy obtained by leaves (Gururani et al. 2015). With the increase of light intensity, qp showed the reverse trend to that of ETR, i.e., it decreased which indicated that the open part of PSII reaction centers was lower and had lower light energy-conversion efficiency (Fig. 3B). With the increase of photosynthetic active radiation, the photoinhibition reduced the quantum yield 
of PSII electron transfer, thus limited photosynthesis and led to the decrease of photochemical efficiency of PSII. According to the results, the $\mathrm{Y}_{\mathrm{II}}$ reduction rate in $54.9 \%$ and $76.4 \%$ shade was higher than that in full sunlight and $94.2 \%$ shade (Fig. $3 C$ ), indicating that the photoinhibition was relatively weaker under $54.9 \%$ and $76.4 \%$ shade and highly shaded seedlings were susceptible to photoinhibition. Photosynthetic quantum yield is affected not only by light intensity but also by light quality; quantum yield of blue and purple light is lower than that of red and yellow light (Hogewoning et al. 2012). The light quality and light intensity under shade conditions both are different from that under full-light conditions (Yoshimura 2010). The proportion of blue and purple light increased under shade conditions. In conclusion, $B$. ochracea could adapt to a variety of light intensities, while suitable shade could improve the ability of seedlings to use light energy and reduce photoinhibition.

The accumulation and transportation of photosynthetic products in plants affect the formation of plant yield and quality (Dong et al. 2019). By changing the canopy temperature, photosynthetic rate, heat dissipation, and pigment profile, the photosynthetic products of plants under shade treatment increased that affected the content and quality of polysaccharides as reported earlier $(\mathrm{Xu}$ et al. 2020). The polysaccharide content of Codonopsis pilosula increased significantly under $44.8 \%$ illumination intensity (Wang et al. 2017). Zheng et al. (2012) reported that Dendrobium candidum under $88 \%$ shade treatment optimized photosynthesis capacity and highly promoted polysaccharide accumulation. In our study, the polysaccharide content of B. ochracea under $76.4 \%$ shade treatment was the highest, which was significantly higher than that under full light. The possible reason is that shade improves photosynthetic capacity, promotes sugar accumulation, and provides more precursors for the synthesis of polysaccharides. Our results indicated that high shade (94.2\%) environment and full-light conditions were not conducive to polysaccharides accumulation in B. ochracea. Variation in light conditions cause changes in the yield of photosynthetic products, which can indirectly affect the accumulation of polysaccharides (Yang et al. 2017, Ye et al. 2017). For example, adjusting light quality improved the photosynthetic capacity and glucose metabolism of Dendrobium officinale, thus increasing the polysaccharide accumulation in protocorm of Dendrobium officinale (Lei et al. 2021). The $76.4 \%$ shade treatment was the most beneficial for the accumulation of polysaccharides in B. ochracea.

\section{References}

Ahemd H.A., Al-Faraj A.A., Abdel-Ghany A.M.: Shading greenhouses to improve the microclimate, energy and water saving in hot regions: A review. - Sci. Hortic.-Amsterdam 201: 36-45, 2016.

Allakhverdiev S.I.: Optimising photosynthesis for environmental fitness. - Funct. Plant Biol. 47: iii-vii, 2020.

Allakhverdiev S.I., Murata N.: Environmental stress inhibits the synthesis de novo of proteins involved in the photodamagerepair cycle of Photosystem II in Synechocystis sp. PCC
6803. - BBA-Bioenergetics 1657: 23-32, 2004

Alyemeni M.N., Ahanger M.A., Wijaya L. et al.: Selenium mitigates cadmium-induced oxidative stress in tomato (Solanum lycopersicum L.) plants by modulating chlorophyll fluorescence, osmolyte accumulation, and antioxidant system. - Protoplasma 255: 459-469, 2018.

Ashraf M., Harris P.J.C.: Photosynthesis under stressful environments: An overview. - Photosynthetica 51: 163-190, 2013.

Bannister J.R., Acevedo M., Travieso G. et al.: The influence of microsite conditions on early performance of planted Nothofagus nitida seedlings when restoring degraded coastal temperate rain forests. - Forest Ecol. Manag. 484: 118957, 2021.

Chen B.L., Yang H.K., Ma Y.N. et al.: Effect of shading on yield, fiber quality and physiological characteristics of cotton subtending leaves on different fruiting positions. Photosynthetica 55: 240-250, 2017.

Dong B., Yang H., Liu H. et al.: Effects of shading stress on grain number, yield, and photosynthesis during early reproductive growth in wheat. - Crop Sci. 59: 363-378, 2019.

Endo T., Uebayashi N., Ishida S. et al.: Light energy allocation at PSII under field light conditions: How much energy is lost in NPQ-associated dissipation? - Plant Physiol. Bioch. 81: 115120,2014

Fang F.Y., Bai S.B., Zhou G.M. et al.: [Effects of shading on growth of Phyllostachys pubescens.] - J. Northeast For. Univ. 40: 11-13, 2012. [In Chinese]

Faseela P., Sinisha A.K., Brestic M., Puthur J.T.: Chlorophyll $a$ fluorescence parameters as indicators of a particular abiotic stress in rice. - Photosynthetica 58: 293-300, 2020.

Gururani M.A., Venkatesh J., Tran L.S.P.: Regulation of photosynthesis during abiotic stress-induced photoinhibition. Mol. Plant 8: 1304-1320, 2015.

Hogewoning S.W., Wientjes E., Douwstra P. et al.: Photosynthetic quantum yield dynamics: from photosystems to leaves. Plant Cell 24: 1921-1935, 2012.

Jiang S., Wang M.Y., Yuan H.W. et al.: Medicinal plant of Bletilla striata: a review of its chemical constituents, pharmacological activities, and quality control. - World J. Tradit. Chin. Med. 6: 393-407, 2020.

Kalmatskaya O.A., Trubitsin B.V., Suslichenko I.S. et al.: Electron transport in Tradescantia leaves acclimated to high and low light: Thermoluminescence, PAM-fluorometry, and EPR studies. - Photosynth. Res. 146: 123-141, 2020.

Lei T., Gao S., Lin X. et al.: Calcium signalling mediated the regulation of growth and polysaccharide accumulation by light quality in Dendrobium officinale protocorms. - Hortic. Environ. Biote. 62: 287-297, 2021

Li J., Yang L., Hou B et al.: Poly p-hydroxybenzyl substituted bibenzyls and phenanthrenes from Bletilla ochracea Schltr with anti-inflammatory and cytotoxic activity. - Fitoterapia 129: 241-248, 2018.

Li Q., Deng M., Xiong Y. et al.: Morphological and photosynthetic response to high and low irradiance of Aeschynanthus longicaulis. - Sci. World J. 2014: 347461, 2014.

Lichtenthaler H.K., Babani F., Langsdorf G.: Chlorophyll fluorescence imaging of photosynthetic activity in sun and shade leaves of trees. - Photosynth. Res. 93: 235-244, 2007.

Lichtenthaler H.K., Babani F., Navrátil M., Buschmann C.: Chlorophyll fluorescence kinetics, photosynthetic activity, and pigment composition of blue-shade and half-shade leaves as compared to sun and shade leaves of different trees. Photosynth. Res. 117: 355-366, 2013.

Lin J., Zhang R., Hu Y. et al.: Interactive effects of drought and shading on Torreya grandis seedlings: Physiological and 
growth responses. - Trees 33: 951-961, 2019.

Liu Y., Qian C., Ding S. et al.: Effect of light regime and provenance on leaf characteristics, growth and flavonoid accumulation in Cyclocarya paliurus (Batal) Iljinskaja coppices. - Bot Stud. 57: 28, 2016.

Liu Y.J., Zhang W., Wang Z.B. et al.: Influence of shading on photosynthesis and antioxidative activities of enzymes in apple trees. - Photosynthetica 57: 857-865, 2019.

Lopez G., Boini A., Manfrini L. et al.: Effect of shading and water stress on light interception, physiology and yield of apple trees. - Agr. Water Manage. 210: 140-148, 2018.

Lü J.H. Li Y.F. Wang X. et al.: [Impact of shading on growth, development and physiological characteristics of Trollius chinensis Bunge]. - Sci. Agr. Sin. 46: 1772-1780, 2013. [In Chinese]

Mathur S., Jain L., Jajoo A.: Photosynthetic efficiency in sun and shade plants. - Photosynthetica 56: 354-365, 2018.

Maxwell K., Johnson G.N.: Chlorophyll fluorescence a practical guide. - J Exp. Bot. 51: 659-668, 2000.

Medina C.L., Souza R.P., Machado E.C. et al.: Response of citrus grown under reflective aluminized polypropylene shading nets. - Sci. Hortic.-Amsterdam 96: 115-125, 2002.

Murchie E.H., Lawson T.: Chlorophyll fluorescence analysis: A guide to good practice and understanding some new applications. - J. Exp. Bot. 64: 3983-3998, 2013.

Niu J., Wang S., Wang B. et al.: Structure and anti-tumor activity of a polysaccharide from Bletilla ochracea Schltr. - Int. J. Biol. Macromol. 154: 1548-1555, 2020.

Paradiso R., de Visser P.H.B., Arena C., Marcelis L.F.M.: Light response of photosynthesis and stomatal conductance of rose leaves in the canopy profile: the effect of lighting on the adaxial and the abaxial sides. - Funct. Plant Biol. 47: 639650, 2020.

Qiao M.Y., Zhang Y.J., Liu L.A. et al.: Do rapid photosynthetic responses protect maize leaves against photoinhibition under fluctuating light? - Photosynth. Res. 149: 57-68, 2021.

Raza M.A., Feng L.Y., Iqbal N. et al.: Effects of contrasting shade treatments on the carbon production and antioxidant activities of soybean plants. - Funct. Plant Biol. 47: 342-354, 2020.

Ruban A.V., Johnson M.P., Duffy C.D.P.: The photoprotective molecular switch in the photosystem II antenna. - BBABioenergetics 1817: 167-181, 2012.

Shao Q., Wang H., Guo H. et al.: Effects of shade treatments on photosynthetic characteristics, chloroplast ultrastructure, and physiology of Anoectochilus roxburghii. - PLoS ONE 9: e85996, 2014.

Shishido Y., Challa H., Krupa J.: Effects of temperature and light on the carbon budget of young cucumber plants studied by steady-state feeding with ${ }^{14} \mathrm{CO}_{2}$. - J. Exp. Bot. 38: 1044-1054, 1987.

Slot M., Krause G.H., Krause B. et al:: Photosynthetic heat tolerance of shade and sun leaves of three tropical tree species. - Photosynth. Res. 141: 119-130, 2019.

Takahashi S., Murata N.: How do environmental stresses accelerate photoinhibition? - Trends Plant Sci. 13: 178-182, 2008.

Tang X., Liu G., Jiang J. et al:: Effects of growth irradiance on photosynthesis and photorespiration of Phoebe bournei leaves. - Funct. Plant Biol. 47: 1053-1061, 2020.

Terashima I., Hanba Y.T., Tholen D., Niinemets Ü.: Leaf functional anatomy in relation to photosynthesis. - Plant Physiol. 155: 108-116, 2011.

Wan G., Najeeb U., Jilani G. et al.: Calcium invigorates the cadmium-stressed Brassica napus L. plants by strengthening their photosynthetic system. - Environ. Sci. Pollut. R. 18: 1478-1486, 2011.
Wang C., Guo Q., Zhu Z., Cheng B.: Physiological characteristics, dry matter, and active component accumulation patterns of Changium smyrnioides in response to a light intensity gradient. - Pharm. Biol. 55: 581-589, 2017.

Wang X., Cao J., Zhang X. et al.: [Effects of topographic factors on leaf traits of apricot in the Loess Plateau, Northwest China.] - Chin. J. Appl. Ecol. 8: 2591-2599, 2019. [In Chinese]

Wellburn A.R.: The spectral determination of chlorophylls a and $b$, as well as total carotenoids, using various solvents with spectrophotometers of different resolution. - J. Plant Physiol. 144: 307-313, 1994.

Wu X., Shu S., Wang Y. et al.: Exogenous putrescine alleviates photoinhibition caused by salt stress through cooperation with cyclic electron flow in cucumber. - Photosynth. Res. 141: 303-314, 2019.

Xu M.Y., Wu K.X., Liu Y. et al.: Effects of light intensity on the growth, photosynthetic characteristics, and secondary metabolites of Eleutherococcus senticosus Harms. Photosynthetica 58: 881-889, 2020.

Xue T., Zhang H., Zhang Y. et al.: Full-length transcriptome analysis of shade-induced promotion of tuber production in Pinellia ternata. - BMC Plant Biol. 19: 565, 2019.

Yang A.J., Anjum S.A., Wang L. et al.: Effect of foliar application of brassinolide on photosynthesis and chlorophyll fluorescence traits of Leymus chinensis under varying levels of shade. - Photosynthetica 56: 873-883, 2018.

Yang B., Tang J., Yu Z. et al.: Light stress responses and prospects for engineering light stress tolerance in crop plants. - J. Plant Growth Regul. 38: 1489-1506, 2019.

Yang W., Liu Y., Fang S. et al.: Variation in growth, photosynthesis and water-soluble polysaccharide of Cyclocarya paliurus under different light regimes. - iForest 10: 468-474, 2017.

Yang X., Tang C., Zhao P. et al.: Antimicrobial constituents from the tubers of Bletilla ochracea. - Planta Med. 78: 606-610, 2012.

Yao X., Li C., Li S. et al.: Effect of shade on leaf photosynthetic capacity, light-intercepting, electron transfer and energy distribution of soybeans. - Plant Growth Regul. 83: 409-416, 2017.

Ye S., Shao Q., Xu M. et al:: Effects of light quality on morphology, enzyme activities, and bioactive compound contents in Anoectochilus roxburghii. - Front. Plant Sci. 8: 857, 2017.

Yi Z., Cui J., Fu Y., Liu H.: Effect of different light intensity on physiology, antioxidant capacity and photosynthetic characteristics on wheat seedlings under high $\mathrm{CO}_{2}$ concentration in a closed artificial ecosystem. - Photosynth. Res. 144: 23-34, 2020.

Yoshimura K.: Irradiance heterogeneity within crown affects photosynthetic capacity and nitrogen distribution of leaves in Cedrela sinensis. - Plant Cell Environ. 33: 750-758, 2010.

Zeng G., Guo Y., Xu J. et al.: Partial shade optimizes photosynthesis and growth in bayberry (Myrica rubra) trees. Hortic. Environ. Biote. 58: 203-211, 2017.

Zhang H., Zhong H., Wang J. et al.: Adaptive changes in chlorophyll content and photosynthetic features to low light in Physocarpus amurensis Maxim and Physocarpus opulifolius "Diabolo". - PeerJ 4: e2125, 2016.

Zhao D., Hao Z., Tao J.: Effects of shade on plant growth and flower quality in the herbaceous peony (Paeonia lactiflora Pall.). - Plant Physiol. Bioch. 61: 187-196, 2012.

Zheng Y., Jiang W., Silva E.N. et al.: Optimization of shade condition and harvest time for Dendrobium candidum plants based on leaf gas exchange, alkaloids and polysaccharides contents. - Plant Omics J. 5: 253-260, 2012.

Zhou H., Zhou G., He Q. et al.: Capability of leaf water content 
and its threshold values in reflection of soil-plant water status in maize during prolonged drought. - Ecol. Indic. 124: 107395, 2021.

Zivcak M., Brestic M., Kalaji H.M., Govindjee: Photosynthetic responses of sun-and shade-grown barley leaves to high light: Is the lower PSII connectivity in shade leaves associated with protection against excess of light? - Photosynth. Res. 119: 339-354, 2014.

(C) The authors. This is an open access article distributed under the terms of the Creative Commons BY-NC-ND Licence. 